\title{
Sex Differences in Competitiveness: Hunter-Gatherer Women and Girls Compete Less in Gender-Neutral and Male-Centric Tasks
}

\author{
Coren L. Apicella • Anna Dreber
}

Received: 18 July 2014 / Revised: 28 October 2014 / Accepted: 29 October 2014 /

Published online: 19 November 2014

(C) Springer International Publishing 2014

\begin{abstract}
Despite numerous attempts to increase workplace equality, the near universal gender wage gap and underrepresentation of women in high status jobs persists in societies around the world. This persistence has led some researchers to speculate that psychological sex differences may be partly to blame. In particular, economists have begun to focus on sex differences in competitiveness as a possible cause. Here we test whether sex differences in competitiveness exist in a relatively isolated and evolutionarily relevant population of hunter-gatherers in Tanzania. In study 1 we examine sex differences in willingness to compete in a gender-neutral task in Hadza adults and children $(N=191)$. We find that when choosing between an individualistic payment scheme and a competitive payment scheme, boys and men are significantly more likely to compete than girls and women. We find no evidence that this sex difference varies with age. In study $2(N=88$ and $N=70)$ we use both a female-centric and a male-centric task to explore sex differences in competitiveness in adults. While we find no sex difference in willingness to compete in the female-centric task, we find that men are more likely to compete in the male-centric task. While further work is needed, this study lends some support to the idea of a sex difference in willingness to compete among hunter-gatherers, but it also highlights the importance of the task type. The observation that a sizable proportion of male Hadza choose to compete in each of the tasks is discussed in light of the fact that hunter-gatherers are largely egalitarian and non-hierarchical.
\end{abstract}

Keywords Sex differences $\cdot$ Competitiveness $\cdot$ Hunter-gatherers and evolution

C. L. Apicella $(\bowtie)$

Department of Psychology, 3720 Walnut Street, Philadelphia, PA 19104, USA

e-mail: corenapicella@gmail.com

\section{A. Dreber}

Department of Economics, Stockholm School of Economics, P.O. Box 6501, 11383 Stockholm, Sweden e-mail: anna.dreber@hhs.se 


\section{Introduction}

When Darwin contrasted the sexes in The Descent of Man (1871) he described man as "rivals of other men" and as the sex that "delight[s] in competition". He had reasoned that many behavioral and physical sex differences, including the weaponry and ornaments seen in males of many species, were the result of sexual selection - males competing for possession of females. Over 100 years later, Darwin's theory of sexual selection, coupled with Trivers' parental investment theory (1972), continues to explain how differences in the patterning of reproduction between males and females can generate further differences between the sexes. Since the costs of reproduction are generally smaller in males compared to females, leading to higher potential rates of reproduction and increased reproductive skew (Bateman 1948; Trivers 1972), males are expected to compete more for mating opportunities, since they have relatively more to gain from them (Clutton-Brock and Parker 1992). From this, it is assumed that selection should not only have favored physical traits that benefit males during contests, but also a psychology that is relatively more eager to compete. As a result, field studies of animals have focused on male-male competition and their ensuing reproductive consequences. These studies have revealed that while male-male competition can be observed in many species across the animal kingdom there is variation in both type and intensity. Generally, male competitive displays and fighting are less intense in monogamous species where there is little or no monopolization of mates, whereas in polygynous species, where the winner takes all, competition tends to be more extreme (Clutton-Brock and Huchard 2013). While female competition has largely been discounted, researchers are now suggesting that females also compete and like males, there is diversity in their competitive behaviors (Clutton-Brock et al. 2006). Even more, some scholars are questioning whether females have been unfairly cast as the passive and more submissive sex.

One reason why female competition has been understudied is because sexual selection has historically emphasized competition for mates, which is undeniably a more male pursuit. Also, when females compete they tend to do so in more subtle ways, compared to males whose competitive behaviors are more overtly expressed (Hrdy 2009) and weaponry visible. Still, it is now becoming increasingly clear that female competition is widespread in many animals (for review see Stockley and Bro-Jorgensen 2011). Although there is evidence that females also compete for mates, it is more common to find them competing for access to resources - resources that can affect their fitness outcomes (Sterck et al. 1997; Rosvall 2011). With this new appreciation for female competition and its potential evolutionary significance, researchers are advocating that the definition of sexual selection be broadened to include all types of competition, including competition for resources ${ }^{1}$ (Clutton-Brock 2009).

While the ecological and social factors that influence female competition have not been firmly established it is thought that high levels of maternal investment should lead to increased competition for high quality resources, including food and shelter (Stockley and Bro-Jorgensen 2011). Thus in mammals, where the energetic demands of pregnancy and lactation are high, female competition should be common; and it is

\footnotetext{
${ }^{1}$ Others contend that selection for resources, or "social selection" as it has been called, should be viewed as a separate subset of natural selection akin to sexual selection (see West-Eberhard 1979).
} 
(see Stockley and Bro-Jorgensen 2011). It is also theorized that female competition should be more intense in gregarious species since there are higher concentrations of individuals competing for the same resources (Snowdon and Pickhard 1999; CluttonBrock and Huchard 2013). Indeed, female competition has been observed in nearly every species of primate - an order of animals known for their high levels of sociality (Hrdy 2009). Competition may also be particularly severe in cooperatively breeding species where one or few females monopolize reproduction (Keller and Reeve 1994; Clutton-Brock et al. 2006). For instance, in wild meerkats it is the competitive female sex that exhibits greater variance in reproductive success and gains more from achieving dominant status (Clutton-Brock et al. 2006). Finally, as previously mentioned, female competition for mates can also occur when males provide direct or indirect benefits to their offspring (Rosvall 2011). For instance, in monogamous species where male care and investment are crucial to the welfare of offspring, females are expected to compete for the best males (Rosvall 2011). Although further work is needed to identify the situations under which female competitive interactions are likely to occur, it is clear than competition between females is common and, analogous to males, it can have reproductive consequences (see Stockley and Bro-Jorgensen 2011). While males may be more competitive than females, it is clear that the traditional approach of dichotomizing male and female psychology may be too simplistic, at least in the realm of competition.

Given what we know about the social and ecological factors that are thought to predict competition in animals should we expect there to be a sex difference in humans? When taking into account human social and reproductive ecology one might predict women to be particularly competitive. This is because humans are 1) notably gregarious, 2) face a distinct reproductive burden and 3) investment by males in offspring is high. Humans are extraordinarily social, existing within complex social groups and networks that comprise both related and unrelated individuals (Apicella et al. 2012). Also, because human babies require high levels of care and nutrition for long-periods of time, human mothers invest heavily in their reproduction. It is estimated that nearly 13 million kilocalories are needed to raise a single infant (Kaplan 1994). Compounding this challenge is the fact that human mothers often have overlapping nutritionally dependent offspring. In consequence, sustained access to high quality resources is essential to a woman's fitness. In fact, it is for this reason it has been suggested that paternal investment and monogamous pair-bonding evolved in humans (Lovejoy 1981; Lancaster and Lancaster 1983). Across foraging societies most men are monogamously pair-bonded and provide some degree of care to their offspring (Apicella and Crittenden 2015, for review). Moreover, women with husbands who contribute more calories to their diet wean their children earlier and achieve greater reproductive success (Marlowe 2001). Similarly, father absence negatively affects children in many societies (Sear and Mace 2008) and children with fathers who have multiple wives are more likely to get sick and die (for review Henrich et al. 2012). Not surprisingly, competition between co-wives can be severe (Burbank 1987). Given the gregarious nature of our species, the high demand for energetic resources and the critical role that fathers play in supporting their wives and children, one might expect female competition to be unusually high in humans. Conversely, male-male competition for mates may be relatively low in men since we are typically more monogamous than our closest primate relatives. There is evidence that body size dimorphism in humans was reduced in the 
human lineage, a finding consistent with a reduction in male-male competition (McHenry 1992; Plavcan 2001).

While a number of social and ecological factors suggest that sex differences in competitiveness should be comparatively smaller in humans, if not absent or reversed, humans may also represent a special case. This is because another hallmark of being human is that we are remarkably cooperative. It has been argued that many of the reproductive challenges faced by women were not solved through competition but rather through cooperation (Hrdy 2005; Ivey 2000; Kramer 2005; Meehan 2005). That is, humans began to cooperate with one another to support their reproductive and parenting needs. Data from a number of foraging societies, where both childcare and food sharing are widespread even among non-kin, support this view of humans as a cooperatively breeding species (Apicella and Crittenden 2015, for review). Furthermore, our dietary niche shifted from small easily procured items, to larger, more difficult-to-acquire food packages necessitating a further need for cooperation between individuals (Kaplan et al. 2000). Thus, it is possible that selection favored cooperative tendencies in women because of the benefits it afforded to their reproduction. That said, some of the work on the evolution of cooperation in humans has instead focused on men as the vector and paradoxically, war or intergroup conflict as the cause (Alexander 1987; Tooby and Cosmides 1988; van Vugt et al. 2007; Kurzban and Leary 2001; Bowles 2009). This argument, which suggests that human prosociality evolved because men who formed coalitions and alliances did better in conflicts and war, suggests that men should be both more cooperative and competitive, depending on the context (van Vugt et al. 2007). In summary, using social and ecological factors to predict sex differences in humans is difficult given the complexity and uniqueness of our species.

By and large, evolutionary claims about the origins of psychological phenomena can largely be thought of as claims about a universal human nature (Cosmides and Tooby 1994). If sex differences in competitiveness are innate, they should persist across a range of environments with only few exceptions. However, it is also recognized that human behavior is flexible and can be shaped by modern environments and culture (Richerson and Boyd 2008; Henrich et al. 2010a). In fact, near universal agreement in some behaviors may instead reflect common exposure to modern circumstance rather than a universal human nature (for an example see Apicella et al. 2014). Thus some evolutionary researchers use hunter-gatherers and other small-scale societies to help inform the nature of our species' psychology (Henrich et al. 2010b).

Here we examine sex differences in competitiveness in an isolated and evolutionarily relevant population of hunter-gatherers: the Hadza. Hunter-gatherers, like the Hadza, are ideal for investigating the evolutionary origins of preferences because they live in a physical and social environment that best approximates the environment where humans spent the majority of their evolution (Marlowe 2010). For the vast majority of time that humans have populated the planet, they have been hunter-gatherers (Lee and Daly 1999). Also, since foragers like the Hadza remain relatively isolated from Western life they may be particularly useful for tests of universality. Indeed, a number of studies have used the Hadza as a model for informing the evolution of human social and economic preferences (Henrich et al. 2001, 2010a; Marlowe 2004; Apicella et al. 2007, 2012, 2014). 
While no study has examined sex differences in willingness to compete in either an isolated or evolutionarily relevant population, researchers have examined it in for example the United States (e.g., Niederle and Vesterlund 2007), Sweden (e.g., Dreber et al. 2014), Colombia (Cárdenas et al. 2012), Armenia (Khachatryan et al. 2014), India (Gneezy et al. 2009; Andersen et al. 2013) and China (e.g., Zhang 2013). ${ }^{2}$ With a few exceptions, men are more likely to select into competitive payment schemes versus piece-rate payment schemes (e.g., Niederle and Vesterlund 2007; Wozniak et al. 2014). However, there are some factors that appear to affect the magnitude of the difference. These include age and task type.

Researchers believe that studying the emergence of sex differences across the lifespan can provide insight into the role of culture versus biology on the development of sex differences. It should be noted that when sex differences emerge later in development they are often attributed to socialization into gender roles. However, one cannot dismiss other potential biological forces that also result later in development, such as puberty. Even with sophisticated models for understanding the effects of socialization, biology and their potential interaction, there is little consensus on how sex differences in competitiveness change with age. While Mayr et al. (2012) find that among adults men are more competitive than women in all age groups, Flory et al. (2012) find that the sex difference is most pronounced among young adults. Boschini et al. (2014) find the opposite. Studying the Khasi in India, Andersen et al. (2013) find that a sex difference, with boys being more competitive, develops around the age of puberty in a patrilineal society, whereas there is no sex difference at any age among children in a matrilineal society.

The type of task also appears to be important. ${ }^{3}$ That is, men and women's competitive inclinations can vary across different domains. For instance, while most studies find that men are more competitive than women if the task is math-related (e.g., Niederle and Vesterlund 2007; Dreber et al. 2014), many studies find that for verbal tasks which are stereotyped to be more female-centric, the sex difference disappears (e.g., Günther et al. 2010; Boschini et al. 2014; Dreber et al. 2014). On the other hand, some studies find no influence of the task on the existence of sex differences in competitiveness (e.g., Dreber et al. 2011; Cárdenas et al. 2012; Wozniak et al. 2014). In light of these previous findings, we examine sex differences in willingness to compete in the Hadza using a gender-neutral task and two culturally specified gender-centric tasks: one for men and one for women. This allows us to explore the extent to which potential sex differences in competitiveness among the Hadza are general or task-specific. While the two gender-centric tasks were conducted with only adults, the gender-neutral task also included children and adolescents so that age-effects could be examined.

It is important to note that most previous studies examining sex differences in competitiveness have done so in mixed-sex settings, where the sex of the opponent is unknown. We employ the same design as these prior studies. This not only allows for a more stringent test of universality, but its relevance to economics and public policy is

\footnotetext{
$\overline{2}$ The first study on sex differences in competitiveness looked at competitiveness as performance change when comparing a forced competition with a piece-rate scheme (Gneezy et al. 2003) but the majority of studies now focus on willingness to compete since this is where sex differences are most often observed.

${ }^{3}$ It should be noted that different studies have employed different tasks which may contribute to the nonuniform results on the impact of sex and age on competitiveness.
} 
stronger. The presence of women in traditionally male-dominated fields is increasing. While our design does not preclude possible same-sex competition, we acknowledge that it is both interesting and important to examine competitiveness in same-sex and opposite-sex groups separately, especially in light of the evolutionary explanations that have been evoked to explain these sex differences. Still, regardless of the exact conditions under which sex differences in a competitive psychology may have evolved, the differences should be robust to a number of settings, including mixed-sex settings.

\section{Methods}

Participants

The Hadza are a population of nomadic hunter-gatherers living in remote regions of Northern Tanzania (for overview see Marlowe 2010). Like the majority of foragers in the ethnographic record, the Hadza practice central place foraging and food sharing, meaning that acquired foods are brought back to a central location and shared with other members of their camp. Camp sizes average around 30 individuals (Marlowe 2010). Serial monogamy best describes the Hadza mating system, though some couples have life-long marriages. Apart from a sexual division of labor there are no other job specializations. Men primarily target animal-based resources and women target plantbased foods. Hunting is generally an individual activity, but occasionally men will hunt in pairs at night by setting up a blind near a water source. Women forage together in small groups of around five individuals though this varies with camp size and the foods foraged (Marlowe 2010). Socialization into gender roles begins at an early age young boys are given bows and arrows around the time they begin walking and girls are given digging sticks. Finally, the Hadza are egalitarian and have no formal dominance hierarchies (Marlowe 2010; Woodburn 1998). While men appear to be slightly dominant to women, it is recognized that Hadza women are independent, vocal and participate in camp level decision-making (Marlowe 2010).

\section{Procedures}

\section{Study 1}

Data were collected from 191 individuals from 16 different Hadza camps on both the Eastern and Western side of Lake Eyasi during the summer of 2010. All participants in each camp deemed old enough to understand the task were invited to participate. Participants' ages ranged from 7 to 70 years old. Ages of the participants were either estimated by one of the authors (Apicella), or when available, taken from previous long-term archival data gathered on the Hadza by the anthropologist Frank Marlowe. Selection of camps relied on a snowball sampling method whereby occupants of the current camp directed the researchers to the next closest camp. While the research was overseen by one of the authors, a Tanzanian research assistant provided instructions to the participants in Swahili, answered their questions and recorded their responses. 
Competitiveness was measured by giving participants a choice on how to be compensated for their performance on a skipping rope task. Participants could either be paid a piece-rate scheme where they would be compensated a quarter-cup of maize for each jump they successfully completed in $30 \mathrm{~s}$ or half-cup of maize for each jump they successfully completed if they completed more jumps than another randomly selected individual living in their camp. Participants were told that if they competed and lost, they would not receive any maize. In order to eliminate potential bias in calculating the number of successful jumps completed by a subject, a jump was considered successful if the subject passed over the rope regardless of whether they jumped, stepped, or tripped over it. The research assistant demonstrated how to use the skipping rope and kept time with a stopwatch. All participants were asked if they understood the research and were encouraged to ask questions. After a participant made their choice, the researcher repeated the chosen payment scheme to the participant to make sure they understood their selection. Participants were given a $30 \mathrm{~s}$ practice period before performance was assessed.

Participant interviews and performance assessments were conducted in private. Reproductive histories were also collected on all adult participants. The skipping rope task took place either behind a large vehicle (e.g. Land Cruiser) or far enough away from camp to ensure privacy from other camp members. Measuring cups were used to describe the payment choices and the researchers visually demonstrated that two of the quarter cups of maize perfectly filled the half-cup measuring cup of maize. All Hadza were told that their individual performance and the person they competed against would be kept secret. At the end of the study participants learned whether they won or lost but were not told the identity of the person they were matched against. Since camps are small and geographically spread out, it is likely the Hadza had a solid understanding of their potential competitors. While the Hadza may have communicated to others about their performance, we do not know if they had a complete understanding of the number of jumps they completed to share with others, since numerical values in their language, Hadzane, do not go past five. Still, some Hadza are able to count to higher numbers in Swahili although we were not aware of anyone who kept track of their jumps. We considered skipping rope to be a gender-neutral since the Hadza do not have access to commercialized skipping ropes nor are they acquainted with western attitudes toward skipping ropes. Finally, skipping ropes are not used in their regular activities or play. ${ }^{4}$

\section{Study 2}

The second study was conducted in the summer of 2013. Adult participants, aged 1971, were recruited from 11 Hadza camps on the Eastern side of Lake Eyasi. Data were collected by a Tanzanian research assistant under the direction of one of the authors (Apicella). Camp selection relied on the same techniques as described in study 1. Competiveness was also measured by giving participants the opportunity to select a competitive payment scheme versus a piece-rate scheme on two different tasks: a bead collection task (female-centric) and a strength (male-centric) task. As in study 1,

\footnotetext{
${ }^{4}$ It should be noted that in 2006 Apicella brought a long skipping rope out to Hadzaland and both sexes played with it. Also, the researcher once witnessed both boys and girls using a vine as a skipping rope.
} 
participants were informed that they would receive a quarter cup of maize for each unit successfully completed on the respective tasks if they chose the piece-rate scheme. Selection into the competitive scheme resulted in a half of cup of maize for each unit completed only if the participant successfully completed more units than another randomly selected participant in their camp, otherwise the participant would receive zero maize. Again, actual measuring cups were used to demonstrate the payment schemes to the participants. As with study 1 performance and choices were assessed in private.

The bead collection task required participants to locate as many red beads as possible from a large bucket containing over 1000 multicolored beads (red, yellow, orange, green white and blue). We chose this task because it is usually the women who make the beaded accessories that are common in Hadza attire. Also, women adorn their waists with thick stands of beads under their clothing and enjoy gifts of beads from researchers. Each red bead found and set aside counted as a completed unit. ${ }^{5}$

The second task was a strength task measured using a dynamometer (Baseline 120286 Electronic Smedley Dynamometer). We considered this a male-centric activity since there is considerable dimorphism in upper-body strength. Also, upper-body strength is a predictor of hunting reputation in Hadza men (Apicella 2014). This finding fits with Hadza intuition about hunting — both Hadza men and women report that having strong arms is the most important physical characteristic for hunting success (Apicella 2014). Finally, stronger upper-bodied Hadza men experience greater reproductive success (Apicella 2014) suggesting that it is evolutionarily significant for men. For this task, each successfully completed unit was measured in number of kilograms squeezed using the dynamometer. The Hadza have experience using the dynamometer with other researchers.

\section{Results}

\section{Study 1: Skipping Rope}

A total of 191 individuals (89 females, 102 males), aged 7 to 70 years old, participated in the first study in the summer of 2010. Consistent with the fact that skipping rope is an unknown activity among the Hadza, we find no sex differences in practice performance (Mann-Whitney $p=0.581$ ) or real performance (Mann-Whitney $p=0.868$ ) in our sample. See Table 1.

Even though there is no sex difference in performance, we find that males are more competitive than females. While $45 \%$ of boys and men chose to compete, only $30 \%$ of girls and women make a similar choice. This difference is statistically significant (Chisquare test $p=0.036$ ), and visualized in Fig. $1{ }^{6}$ In a regression analysis using OLS regressions with robust standard errors, we also find that this sex difference in competiveness remains when controlling for practice jumps, actual performance in jumps, age and age-squared (all $p<0.05$, see the Appendix for all regression tables). ${ }^{7}$

\footnotetext{
$\overline{{ }^{5}}$ This task vaguely resembles the cork collection task in Sutter and Rützler (in press).

${ }^{6}$ Chi-square and Mann-Whitney U tests give similar results to the p-values from the tests of proportions reported in the main text.

${ }^{7}$ We have also performed logit regressions for all three competitiveness and the results are qualitatively the same as for OLS. We rely on the OLS regressions since interaction effects cannot easily be evaluated with logit regressions (Ai and Norton 2003).
} 
Table 1 Summary statistics, skipping rope

\begin{tabular}{llll}
\hline & All & Males & Females \\
\hline Practice jumps & $M=21.74$ & $M=21.35$ & $M=22.19$ \\
& $S . D .=10.68$ & $S . D .=10.50$ & $S . D .=10.91$ \\
& $N=191$ & $N=102$ & $N=89$ \\
Performance & $M=25.28$ & $M=25.22$ & $M=25.36$ \\
(jumps) & $S . D .=10.21$ & $S . D .=9.84$ & $S . D .=10.68$ \\
& $N=191$ & $N=102$ & $N=89$ \\
Competing & $M=0.38$ & $M=0.45$ & $M=0.30$ \\
$(1=$ yes, 0=no) & $S . D .=0.49$ & $S . D .=0.50$ & $S . D .=0.46$ \\
& $N=191$ & $N=102$ & $N=89$ \\
Age & $M=29.98$ & $M=30.57$ & $M=29.30$ \\
(years) & $S . D .=13.32$ & $S . D .=13.72$ & $S . D .=12.90$ \\
& $N=191$ & $N=102$ & $N=89$ \\
Reproductive success & $M=2.83$ & $M=2.56$ & $M=3.19$ \\
(children alive) & $S . D .=2.28$ & $S . D .=2.27$ & $S . D .=2.26$ \\
& $N=121$ & $N=68$ & $N=53$ \\
\hline
\end{tabular}

Given the growing literature on the impact of age on sex differences in competitiveness, we also test whether there is an interaction between the age variables (i.e. age and agesquared) and sex on willingness to compete. This allows us to explore whether the sex difference is more pronounced in younger or older individuals. We do not find any evidence of an interaction between age and sex $(p=0.141)$ or age-squared and sex $(p=$ 0.103). Lastly, we test whether the effect of performance on willingness to compete interacts with sex i.e. differs for boys and men versus girls and women. This is not the case, since this interaction is also insignificant $(p=0.904)$.

We do not know whether our participants had an accurate representation of their performance relative to other participants. If our participants had some knowledge of their relative performance and were attempting to maximize their expected earnings, we should find higher rates of competing among participants who completed at least 28 successful jumps which is the median amount of jumps completed by the Hadza. Assuming that participants are indifferent between competing when they perform as the median participant, we identified 98 (out of 191) individuals who would have done better to compete (i.e. they completed $\geq 28$ jumps). Out of these 98 participants, 44 (45\%) chose to compete. In contrast, only 29 out of 93 (31\%) participants that should not have competed did so. The difference between these two groups in their willingness to compete is marginally significant (test of proportions $p=0.051$ ). Thus, even though the performance variable is not significantly related to competitiveness, there is some evidence that those who should compete did so. Of course, this variable could be endogenous: any individual forced to compete may perform better under the competitive pressure. We conducted additional exploratory analyses to examine the role of median performance on willingness to compete in men and women separately. We find that out of the 50 men that should have competed, 29 (58\%) did so. Only 17 out of the 52 men $(33 \%)$ that should not have competed chose to compete. This difference is 


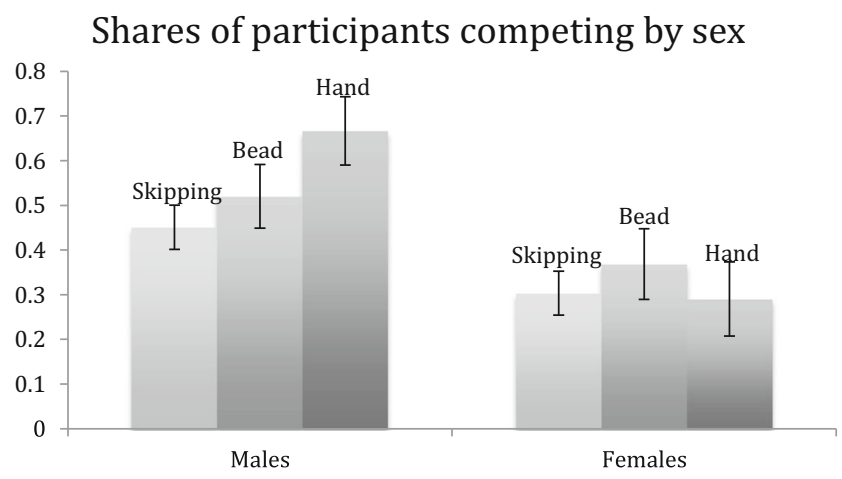

Error bars are the standard error of the mean.

Fig. 1 Competitiveness in the three tasks. Error bars are the standard error of the mean.

statistically significant (Chi-square test $p=0.010$ ). For women, only 15 out of the 48 (31\%) women who should have competed did so and 12 out of 41 (29\%) who should not have competed did. This difference is not statistically significant (Chi-square test $p=0.839$ ). Our results suggest that men, but not women, are more likely to compete when it benefits them.

Finally, we test whether we can predict reproductive success, defined as the number of living children, by willingness to compete in skipping rope. For this, we perform a regression analysis, where reproductive success is the dependent variable. Independent variables include sex (being female), age, age-squared, competitiveness and actual performance in the task. We also include an interaction between sex and competitiveness in order to test whether any potential correlation between reproductive success and competitiveness differs in men and women. We find neither a significant main effect of competitiveness $(p=0.763)$ nor a significant interaction between sex and competitiveness $(p=0.121)$ on reproductive success. We also find no significant effect for men ( $p=$ 0.412 ) and women separately $(p=0.590)$. (See the Appendix for all regression tables.)

\section{Study 2: Bead Collection and Handgrip Strength}

A total of 88 individuals (38 females, 50 males) and 70 individuals (31 females, 39 males) participated in the bead collection task and the handgrip strength task, respectively, during the summer of 2013.

\section{Bead Collection}

Even though women collected more beads in point estimates than men (see Table 2), this difference is not significant (Mann-Whitney $p=0.146$ ). For competitiveness, the point estimate suggests that men are more competitive. While over half $(52 \%)$ of men chose to compete, only $37 \%$ of women chose to compete (see Fig. 1). This difference, however, is also not significant (Chi-square $p=0.157$ ).

We employ the same regression analysis techniques as we did in study 1 . Specifically, we examine the role of sex, performance, age and age-squared on willingness to compete. Likewise, we also examine whether there is an interaction between age (and age-squared) and sex on willingness to compete and an interaction between sex and 
performance on willingness to compete. We find no significant sex difference in willingness to compete in the bead task (all $p>0.05$ ). Moreover, we find no significant interactions between either age and sex $(p=0.402)$, age-squared and sex $(p=0.421)$ or performance and sex on willingness to compete $(p=0.490)$.

It is interesting to note that performance itself is not significantly related to competitiveness in any of the specifications in Table A3. As in study 1, we test whether those who should have competed in the bead collection task, chose to do so. With the median performance being six beads collected, we find that 24 out of 52 (46\%) participants who collected more than six beads chose to compete. Out of 36 participants that should not have competed (i.e. collected $<6$ beads), 16 (44\%) chose to compete. This difference is not statistically significant (Chi-square test $p=0.874$ ). For men, 14 out of the $26(54 \%)$ men that should have competed, did so. Out of the 24 men that should not compete, $12(50 \%)$ do so anyway. We do not find a significant difference in willingness to compete between men who collected more than six beads and men who collected less than six beads (Chi-square test $p=0.786$ ). For women, 10 out of the 26 (38\%) women who should have competed did so, while 4 out of the 12 (33\%) women that should not have competed did so anyway. As with the men, this difference is not statistically significant (Chi-square test $p=0.761$ ). These results suggest that objective probabilities of winning were not factored into participants' decisions to compete. However, we do not know whether subjective beliefs played a role.

We also test whether competitiveness in the bead collection task can predict reproductive success. While there is no significant main effect of competitiveness $(p=0.258)$ on reproductive success, there is a marginally significant positive interaction between sex (being a woman) and competitiveness $(p=0.051)$. Thus we perform separate regressions for each sex. For men the relationship between reproductive success and competitiveness is not significant $(p=0.703$. For women there is a marginally significant positive relationship $(p=0.052)$, suggesting that females who are competitive in the bead collection task have approximately 1.6 more surviving children.

Table 2 Summary statistics, bead collection

\begin{tabular}{llll}
\hline & All & Males & Females \\
\hline $\begin{array}{l}\text { Performance } \\
\text { (beads collected) }\end{array}$ & $M=6.13$ & $M=5.86$ & $M=6.47$ \\
& $S . D .=2.02$ & $S . D .=1.86$ & $S . D .=2.19$ \\
Competing $(1=$ yes, $0=$ no) & $N=88$ & $N=50$ & $N=38$ \\
& $M=0.45$ & $M=0.52$ & $M=0.37$ \\
& $S . D .=0.50$ & $S . D .=0.50$ & $S . D .=0.49$ \\
Age & $N=88$ & $N=50$ & $N=38$ \\
(years) & $M=39.25$ & $M=39$ & $M=39.58$ \\
& $S . D .=12.34$ & $S . D .=11.29$ & $S . D .=13.76$ \\
Reproductive success & $N=88$ & $N=50$ & $N=38$ \\
children alive) & $M=3.30$ & $M=3.11$ & $M=3.54$ \\
& $S . D .=2.34$ & $S . D .=2.36$ & $S . D .=2.33$ \\
& $N=84$ & $N=47$ & $N=37$ \\
\hline
\end{tabular}




\section{Handgrip Strength}

In the male-centric handgrip strength task, men pull significantly more weight than women (Mann-Whitney $p<0.0001$ ). Not surprisingly, men are also significantly more competitive than women (Chi-square test $p=0.002$ ). While $67 \%$ of men chose to compete, only $29 \%$ of women make the same choice. See Table 3 and Fig. 1.

Further regression analyses were performed in order to further understand this sex difference in willingness to compete. We use OLS regressions, with robust standard errors, and add controls for sex, performance, age and age-squared. In addition, we examine whether there is an interaction between age (and age-squared) and sex on willingness to compete and an interaction between sex and performance on willingness to compete. The sex difference in competitiveness is no longer significant (female: $p=$ 0.323 ) once we control for performance (see Table A5). Instead, we find that performance (i.e. weight pulled) significantly predicts willingness to compete $(p=0.007)$. This suggests that it is not sex per se that predicts competitiveness in this task, but rather performance - men tend to be physically stronger than women. None of the interactions tested are significant (age and sex interaction: $p=0.761$; age-squared and sex interaction: $p=0.612$; performance and sex interaction: $p=0.138$ ).

While there is already some evidence that individuals who should have competed in the task did so (i.e. men), we systematically compare the proportion of participants who chose to compete in two groups: 1) those who performed better than the median participant and 2) those who performed worse than the median participant. The median performance in the task is $26.1 \mathrm{~kg}$ pulled. Out of the 35 participants who pulled more than $26.1 \mathrm{~kg}$ of weight, 25 (71 \%) of them chose to compete. In contrast, only 10 out of the $35(29 \%)$ who pulled less than $26.1 \mathrm{~kg}$ chose to compete. This difference is statistically significant (Chi-square test $p=0.0003$ ). When we examine each sex separately, we find that 22 out of the 30 men $(73 \%)$ who performed better than the median participant chose to compete and four out of the 9 men (44\%) that performed worse than the median participant chose to compete. This difference is not statistically

Table 3 Summary statistics, handgrip strength

\begin{tabular}{llll}
\hline & All & Males & Females \\
\hline $\begin{array}{l}\text { Performance } \\
\text { (weight pulled, kg) }\end{array}$ & $M=28.72$ & $M=34.31$ & $M=21.70$ \\
& $S . D .=9.78$ & $S . D .=9.08$ & $S . D .=4.92$ \\
Competing & $N=70$ & $N=39$ & $N=31$ \\
$(1=$ yes, 0=no) & $M=0.50$ & $M=0.67$ & $M=0.29$ \\
& $S . D .=0.50$ & $S . D .=0.48$ & $S . D .=0.46$ \\
Age & $N=70$ & $N=39$ & $N=31$ \\
(years) & $M=39$ & $M=38.41$ & $M=39.74$ \\
& $S . D .=12.09$ & $S . D .=10.24$ & $S . D .=14.22$ \\
Reproductive success & $N=70$ & $N=39$ & $N=31$ \\
(children alive) & $M=3.40$ & $M=3.24$ & $M=3.6$ \\
& $S . D .=2.31$ & $S . D .=2.25$ & $S . D .=2.40$
\end{tabular}


significant (Chi-square test $p=0.107$ ) but note the small sample size. Three out of the five women $(60 \%)$ who performed better than the median participant competed and six out of the 26 women $(23 \%)$ who performed worse than the median participant competed. This difference is marginally significant at the $10 \%$ level (Chi-square test $p=0.096$ ) but again, note the small sample size. For this task there is some evidence that those that should compete did so. Participants in this study may have been aware of their relative strength and used this knowledge when deciding whether to compete. Interestingly, this is the task with which the Hadza have had the most experience.

Finally, we test whether competitiveness in handgrip strength can predict reproductive success. There is neither a significant main effect of competitiveness on reproductive success $(p=0.702)$, nor a significant interaction between sex and competitiveness $(p=0.240)$. Even so, there is a significant positive relationship between reproductive success and competitiveness for women including controls $(p=0.045)$, whereas there is no significant relationship for males $(p=0.457)$. On average, women who compete have approximately two more children than women who do not compete.

\section{Discussion}

Our primary motivation for studying sex differences in the Hadza stems from the observation that financial and labor outcome disparities exist between the sexes across many societies. Men typically reach higher positions and earn more, despite the fact that women are, on average, more educated (e.g., Croson and Gneezy 2009; Bertrand 2010). One proposition recently brought forward by economists is that these disparities may, in part, result from sex differences in economic preferences such as willingness to compete. The suggestion that men may be more competitively inclined than women is not new to the field of evolutionary psychology; it is in fact central to the theories of sexual selection (Darwin 1871) and parental investment (Trivers 1972). Nevertheless, this is the first study to examine sex differences in competitiveness, as measured by economists, in an evolutionarily relevant population of hunter-gatherers.

In all three tasks that we explore, the point estimates suggest that Hadza boys and men are more competitive than Hadza girls and women. This difference however, is only significant for the gender-neutral task (skipping rope) and the male-centric task (handgrip strength). Boys and men are significantly more competitive than girls and women in skipping rope, even though they perform equally well when it comes to both practice jumps and actual performance. The sex difference in competitiveness found for handgrip strength, with men competing more than females, is less surprising since men are typically stronger than women. Rationally, it makes sense for women to choose to be compensated with a piece-rate scheme on the handgrip strength task since they perform, on average, worse than half of the adult population (i.e. men). While the point estimate suggests that women perform better at the bead task than men, the difference is not significant. Future work with the Hadza on competiveness should also employ a task, which is not only female-centric, but also one where women excel. Such a task did not exist in the current study and it is possible that women would be more competitive than men in such a situation. Previous studies have found that confidence can explain some of the sex difference (Niederle and Vesterlund 2007). An interesting follow-up to this study would also measure confidence in addition to performance. Nevertheless, we 
still find a strong sex difference in willingness to compete in a largely unfamiliar, gender-neutral task where the sexes perform equally well. This sex difference is also robust to the addition of controls. Taken together, our results highlight the importance of task type when exploring topics such as sex differences in competitiveness since the results are not easily generalizable from one task to another.

Sexual selection concerns competition between same sex conspecifics, yet most studies that examine sex differences in willingness to compete do so within mixed-sex environments. Future work on sex differences in competitiveness among groups like the Hadza could further benefit from exploring how sex and group membership of potential competitors could influence preferences to compete. It is possible that the Hadza may be more willing to compete against same sex individuals or alternatively, against the sex that is typecast to perform worse at the task. Interestingly, previous work on the sex of the opponent finds mixed results for its impact on the willingness to compete (e.g., Gneezy et al. 2003; Gneezy and Rustichini 2004; Datta Gupta et al. 2013). Similarly, sex differences in competitiveness between non-campmates, including other Hadza or individuals from other ethnic groups, could also be explored. It is possible that the sex difference in competitiveness are exaggerated when potential opponents are out-group members since it is generally men who directly engage in intergroup conflict and war. Previous experimental work has found that men become more cooperative with their in-group members during intergroup conflicts while women are unaffected by such conflicts and rivalries (van Vugt et al. 2007).

It is important to note that a significant proportion of men in our studies chose to compete. Depending on the task, between 45 and $67 \%$ of our male participants chose to compete. The significance of this finding is underscored when one considers the egalitarian and non-hierarchical nature of hunter-gatherers like the Hadza. ${ }^{8}$ If there are little or no dominance hierarchies within or between the sexes then one might expect that there should also be little need for competition - especially if food items are shared. In the current study, we use maize as our currency. One consequence of using this currency source is that earnings were likely pooled and distributed equally among camp members. This is common practice with many resources, including meat and foods, like maize, that require processing. Typically, when the Hadza receive maize, women grind it together in a group before it can be cooked into ugali. The findings suggest that despite the egalitarian nature of the Hadza, male competition exists and was likely present in our hunter-gatherer ancestors. These findings also potentially help to inform an important and current debate among anthropologists about hunter-gatherer subsistence: the question of why men hunt.

There are two competing views as to why men hunt, though they are not mutually exclusive. On one side of the debate, researchers view hunting as a means by which men provision their families (Lancaster 1978). Meat is a high caloric resource that is rich in nutrients, fat, digestible proteins and amino acids - properties that cannot be found in foraged foods on the savannah (Domínguez-Rodrigo et al. 2013). However, compared to foraged foods, meat is less reliably secured and more widely shared and as a result may generate fewer calories in the long run. For these reasons, it has been

\footnotetext{
${ }^{8}$ Other results from economic games played with the Hadza also have challenged this view of the Hadza as always behaving fairly and generously. For example, compared to other small-scale societies the Hadza are on the lower end of ultimatum game offers (Henrich et al. 2001) and dictator game offers (Henrich et al. 2010b).
} 
suggested that hunting instead serves as a form of male-male competition used to attract mates (Hawkes 2001; Hawkes and Bliege Bird 2002; Smith 2004; Hawkes et al. 2014). Specifically, it has been argued that hunting is a means by which men signal their quality to the opposite sex. It is possible that the sexual division of labor observed in the vast majority of hunter-gatherer societies reflects sex differences in competitive preferences, though other outlets for competing may exist. Interestingly, in Tsimane foragers, a differential hormonal response to hunting was observed when comparing successful and unsuccessful hunts in men (Trumble et al. 2014). Specifically, the successful killing of prey by a hunter was met with a relative rise in his testosterone. This differential response in testosterone is aptly called the winner-loser effect and has been observed to occur in men following numerous types of competition, including physical (e.g. Elias 1981), cognitive (e.g. Mazur et al. 1992) and political contests (Stanton et al. 2009; Apicella and Cesarini 2011). While this could be taken as evidence that men physiologically respond to hunting successes and failures as though they are competitions, the researchers do not view it as evidence that men are hunting to gain a status advantage. This is because the increase in testosterone was not found to be related to the size of the kill (e.g. how shareable it is) or to the number of individuals present in the community (e.g. audience effects). Instead it was argued that that men are more psychologically attuned to the provisioning benefits of the kill rather than the signaling benefits. Still, little work has examined whether this differential response is equally sensitive to big versus small wins, narrow versus decisive matches and/or audience effects, so we believe that this conclusion may be premature. ${ }^{9}$ Whatever the reason for why men hunt, the evidence suggests that hunting may serve as a form of competition between men. Men are not only more competitive than women and respond physiologically to hunting as though it is a competition, but hunting ability is positively associated with increased reproductive success in a number of forager societies (Marlowe 1999; Hill and Hurtado 1996; Kaplan and Hill 1985; Wiessner 2002; Apicella 2014). Thus, there is selection for better hunters and so competition, at least in the evolutionary sense, occurs.

In this paper we explore how different tasks may affect sex differences in willingness to compete. Another avenue for future research would be to examine the role of compensation and reward. It is possible that individually consumable items, or other goods with lower rates of taxation, might induce more competition among one sex or both sexes. The current study used maize, which was likely pooled and shared among the participants. There may be benefits to winning maize aside from its consumption value. If bringing in more food provides a status boost, as has been suggested with hunted meat, it is possible that shared items generate more competition than individually consumable items. Men may be more inclined to compete when reputation is at stake. In addition, providing more food to a common pot could also benefit individuals if it induces feelings of gratitude and indebtedness in others. Finally, in so far as the Hadza track individual contributions to public goods, shared food resources may result

\footnotetext{
${ }^{9}$ In fact, it has been theoretically suggested and empirically demonstrated (in women) that narrow or close call defeats should result in greater increases in testosterone so as to encourage more dominance seeking behaviors (see Zilioli et al. 2014). Thus a small kill may in fact result in higher testosterone levels to promote hunting of bigger game. However, see Mehta et al. (current issue) who report that rises in testosterone in men following decisive wins predicts their propensity to compete but does not find the same relationship in men whose victories were close calls.
} 
in increased awareness of who won and lost the competition - an outcome that may also serve to enhance or diminish status. While the Hadza may not have any formalized dominance hierarchies, they do show agreement when ranking men according to their hunting ability (Apicella 2014). Again, it is possible that different reward types may induce more competition among one or both sexes. Likewise, payment structures may also be relevant. For instance, competing involves greater risk and this may lead to greater disparities between the sexes. However, most studies controlling for risk preferences find that the gender gap remains significant (see, e.g., Niederle and Vesterlund 2007).

As mentioned, the Hadza are largely egalitarian and do not have any clear dominance hierarchies. As such, it is possible that overt or showy competitive displays may be absent or discouraged in the Hadza. For instance, boasting and grandiloquence are notably absent in hunter-gatherers like the !Kung (Lee and Daly 1999). In the current study, we examined willingness to compete in private. Also, assigned partners in the competition were unknown to the participants. If the question of whether to compete was asked in a public setting, Hadza participants may have been more reluctant to compete (personal communication, Nick Blurton Jones, Oct 2014). This would be an interesting and important follow-up to this study.

We conduct exploratory analyses to examine whether willingness to compete is related to reproductive success in men and women. While we acknowledge that our measure for competitiveness is binary and therefore ignores potentially important variation in preferences, we find no evidence in the current sample that men who compete experience increased reproductive success. For men, reproductive success may not only be influenced by willingness to compete but also by ability to win. That is, the outcome of the competitions they engage in should matter to their reproductive success. Interestingly, we find some evidence suggesting that the women who chose to compete in our sample have more children than those who do not: this relationship appears as marginally significant in the bead collection task and significant in the handgrip strength task. Again, these are exploratory analyses, but similar findings have been found in other mammals and in particular, cooperatively breeding species (for review see Stockley and Bro-Jørgensen 2011). Nevertheless, this finding should be replicated in a larger sample of Hadza women, using other measures of competitiveness before too much weight is placed on the result. Moreover, we are not able to determine cause and effect. While having more children could increase competitiveness in women, competitiveness itself could confer a reproductive advantage. If there is a fitness advantage, it could be obtained through any number of channels. For instance, it is possible that competitive women obtain more or higher quality foods and/or higher quality mates. It is also possible that competitiveness preferences are instead correlated with other phenomena and behaviors that directly affect fitness outcomes. We advocate for further research on female competition including its forms and consequences.

To our knowledge, this is the first study to examine sex differences in competitiveness in a hunter-gatherer population despite the suggestion, by some, that the sex difference is an inherited feature of our species psychology. To the extent that the Hadza can be used to inform the behaviors of our early human ancestors, the results indicate that sex differences in competitiveness, at least in some domains, were also present in our early human ancestors. The sex difference in willingness to compete is common among many societies (e.g. Croson and Gneezy 2009; Niederle and 
Vesterlund 2007; Almås et al. 2012; Datta Gupta et al. 2013; Sutter and Rützler 2014), a finding consistent with the explanation that natural selection favored a more competitive male psychology. Still, these results are preliminary since only one measure of competitiveness was examined and in only three domains. Future work should employ other measures of competitiveness, across a variety of domains, and examine the possible influence of reward type and structure.

Acknowledgments We would like to thank our research assistants, Ibrahim Mabulla, Mika Peterson, Deus Haraja and Charles Ndefu and the Hadza for their participation. We would also like to thank seminar participants at the University of Zurich, HECER and The PLEEP Lab as well as two reviewers for their thoughtful feedback and suggestions. This research was supported from funding from the University of Pennsylvania. Anna Dreber Almenberg is thankful from support from the Jan Wallander and Tom Hedelius Foundation (Svenska Handelsbankens Forskningsstiftelser) as well as the Knut and Alice Wallenberg Foundation.

\section{Appendix}

Table 4 Competitiveness in skipping rope, OLS regression

\begin{tabular}{|c|c|c|c|c|c|c|}
\hline & All & All & All & All & All & All \\
\hline Female & $\begin{array}{l}-0.148^{* *} \\
(0.0697)\end{array}$ & $\begin{array}{l}-0.155^{* *} \\
(0.0685)\end{array}$ & $\begin{array}{l}-0.150 * * \\
(0.0686)\end{array}$ & $\begin{array}{l}-0.158 * * \\
(0.0682)\end{array}$ & $\begin{array}{l}-0.542 * \\
(0.312)\end{array}$ & $\begin{array}{l}-0.178 \\
(0.174)\end{array}$ \\
\hline Practice jumps & & $\begin{array}{l}0.00872 * * * \\
(0.00316)\end{array}$ & $\begin{array}{l}0.00146 \\
(0.00575)\end{array}$ & $\begin{array}{l}0.00326 \\
(0.00576)\end{array}$ & $\begin{array}{l}0.00439 \\
(0.00588)\end{array}$ & $\begin{array}{l}0.00331 \\
(0.00582)\end{array}$ \\
\hline Performance & & & $\begin{array}{l}0.00921 \\
(0.00596)\end{array}$ & $\begin{array}{l}0.00586 \\
(0.00620)\end{array}$ & $\begin{array}{l}0.00475 \\
(0.00641)\end{array}$ & $\begin{array}{l}0.00539 \\
(0.00785)\end{array}$ \\
\hline Age & & & & $\begin{array}{l}0.0218^{* *} \\
(0.00986)\end{array}$ & $\begin{array}{l}0.0109 \\
(0.0146)\end{array}$ & $\begin{array}{l}0.0221^{* *} \\
(0.0100)\end{array}$ \\
\hline $\mathrm{Age}^{\wedge} 2$ & & & & $\begin{array}{l}-0.000351^{* *} \\
(0.000145)\end{array}$ & $\begin{array}{l}-0.000186 \\
(0.000195)\end{array}$ & $\begin{array}{l}-0.000354^{* *} \\
(0.000147)\end{array}$ \\
\hline Age*female & & & & & $\begin{array}{l}0.0307 \\
(0.0208)\end{array}$ & \\
\hline $\mathrm{Age}^{\wedge} 2 *$ female & & & & & $\begin{array}{l}-0.000503 \\
(0.000307)\end{array}$ & \\
\hline Performance*female & & & & & & $\begin{array}{l}0.000802 \\
(0.00668)\end{array}$ \\
\hline Constant & $\begin{array}{l}0.451^{* * *} \\
(0.0495)\end{array}$ & $\begin{array}{l}0.265^{* * *} \\
(0.0814)\end{array}$ & $\begin{array}{l}0.187 * * \\
(0.0946)\end{array}$ & $\begin{array}{l}-0.0413 \\
(0.190)\end{array}$ & $\begin{array}{l}0.111 \\
(0.264)\end{array}$ & $\begin{array}{l}-0.0333 \\
(0.207)\end{array}$ \\
\hline Observations & 191 & 191 & 191 & 191 & 191 & 191 \\
\hline R-squared & 0.023 & 0.059 & 0.071 & 0.093 & 0.103 & 0.093 \\
\hline
\end{tabular}

Robust standard errors in parentheses

*** $p<0.01, * * p<0.05, * p<0.1$ 
Table 5 Reproductive success and competitiveness in skipping rope, OLS regression

\begin{tabular}{lllll}
\hline & All & All & Males & Females \\
\hline Female & $0.700^{*}$ & 0.270 & & \\
& $(0.366)$ & $(0.494)$ & & $0.452^{* * *}$ \\
Age & $0.304^{*}$ & $0.313^{*}$ & 0.251 & $(0.138)$ \\
& $(0.160)$ & $(0.165)$ & $(0.232)$ & $-0.00510^{* * *}$ \\
Age`2 & -0.00277 & -0.00285 & -0.00183 & $(0.00190)$ \\
& $(0.00228)$ & $(0.00235)$ & $(0.00322)$ & 0.300 \\
Competing & -0.132 & -0.591 & -0.510 & $(0.553)$ \\
& $(0.437)$ & $(0.574)$ & $(0.617)$ & -0.00215 \\
Performance & -0.00798 & -0.00732 & -0.0150 & $(0.0263)$ \\
Competing*female & $(0.0228)$ & $(0.0230)$ & $(0.0363)$ & \\
& & 1.121 & & $-5.855^{* *}$ \\
Constant & & $(0.718)$ & & $(2.302)$ \\
Observations & -4.186 & -4.207 & -3.232 & 53 \\
R-squared & $(2.836)$ & $(2.904)$ & $(4.279)$ & 0.180 \\
\hline
\end{tabular}

Robust standard errors in parentheses

$* * * p<0.01, * * p<0.05, * p<0.1$

Table 6 Competitiveness in bead collection, OLS regression

\begin{tabular}{|c|c|c|c|c|c|}
\hline & All & All & All & All & All \\
\hline \multirow[t]{2}{*}{ Female } & -0.152 & -0.175 & -0.158 & 0.735 & -0.389 \\
\hline & $(0.107)$ & $(0.106)$ & $(0.108)$ & $(1.059)$ & $(0.347)$ \\
\hline \multirow[t]{2}{*}{ Performance } & & 0.0374 & 0.0322 & 0.0297 & 0.0136 \\
\hline & & $(0.0266)$ & $(0.0270)$ & $(0.0277)$ & $(0.0393)$ \\
\hline \multirow[t]{2}{*}{ Age } & & & 0.0134 & 0.0388 & 0.0142 \\
\hline & & & $(0.0262)$ & $(0.0384)$ & $(0.0271)$ \\
\hline \multirow[t]{2}{*}{$\operatorname{Age}^{\wedge} 2$} & & & -0.000202 & -0.000497 & -0.000206 \\
\hline & & & $(0.000309)$ & $(0.000457)$ & $(0.000318)$ \\
\hline \multirow[t]{2}{*}{ Age*female } & & & & -0.0442 & \\
\hline & & & & $(0.0525)$ & \\
\hline \multirow[t]{2}{*}{$\operatorname{Age}^{\wedge} 2 *$ female } & & & & 0.000499 & \\
\hline & & & & $(0.000617)$ & \\
\hline \multirow[t]{2}{*}{ Performance*female } & & & & & 0.0375 \\
\hline & & & & & $(0.0541)$ \\
\hline \multirow[t]{2}{*}{ Constant } & $0.520 * * *$ & $0.301^{*}$ & 0.142 & -0.350 & 0.225 \\
\hline & $(0.0715)$ & $(0.170)$ & $(0.575)$ & $(0.774)$ & $(0.581)$ \\
\hline Observations & 88 & 88 & 88 & 88 & 88 \\
\hline R-squared & 0.023 & 0.045 & 0.057 & 0.066 & 0.063 \\
\hline
\end{tabular}

Robust standard errors in parentheses

*** $p<0.01, * * p<0.05, * p<0.1$ 
Table 7 Reproductive success and competitiveness in bead collection, OLS regression

\begin{tabular}{lllll}
\hline & All & All & Males & Females \\
\hline Female & 0.601 & -0.222 & & \\
& $(0.498)$ & $(0.669)$ & & 0.200 \\
Age & $0.259^{* * *}$ & $0.276^{* * *}$ & $0.363^{* *}$ & $(0.125)$ \\
Age`2 & $(0.0938)$ & $(0.0932)$ & $(0.169)$ & -0.00188 \\
& $-0.00239^{* *}$ & $-0.00255^{* *}$ & -0.00335 & $(0.00136)$ \\
Competing & $(0.00113)$ & $(0.00110)$ & $(0.00213)$ & $1.554^{*}$ \\
& 0.564 & -0.246 & -0.262 & $(0.771)$ \\
Performance & $(0.495)$ & $(0.648)$ & $(0.683)$ & 0.0722 \\
& 0.0566 & 0.0289 & -0.0517 & $(0.179)$ \\
Competing*female & $(0.117)$ & $(0.118)$ & $(0.172)$ & \\
& & $1.951^{*}$ & & -2.142 \\
Constant & & $(0.983)$ & & $(3.058)$ \\
Observations & $-3.704^{* *}$ & $-3.507^{*}$ & $-5.112^{*}$ & 37 \\
R-squared & $(1.843)$ & $(1.886)$ & $(2.736)$ & 0.172 \\
\hline
\end{tabular}

Robust standard errors in parentheses

*** $p<0.01, * * p<0.05, * p<0.1$

Table 8 Competitiveness in handgrip strength, OLS regression

\begin{tabular}{llllll}
\hline & All & All & All & All & All \\
\hline Female & $-0.376^{* * *}$ & -0.150 & -0.148 & -0.268 & $-0.774^{*}$ \\
& $(0.113)$ & $(0.151)$ & $(0.155)$ & $(1.176)$ & $(0.436)$ \\
Performance & & $0.0179^{* * *}$ & $0.0164^{* *}$ & $0.0174 * *$ & 0.0125 \\
& & $(0.00642)$ & $(0.00688)$ & $(0.00721)$ & $(0.00760)$ \\
Age & & 0.0180 & -0.00170 & 0.00904 \\
& & & $(0.0250)$ & $(0.0480)$ & $(0.0261)$ \\
Age`2 & & -0.000234 & $8.74 \mathrm{e}-05$ & -0.000110 \\
& & & $(0.000279)$ & $(0.000576)$ & $(0.000298)$ \\
Age*female & & & 0.0174 & \\
& & & & $(0.0570)$ & \\
Age`2*female & & & -0.000337 & \\
& & & & $(0.000661)$ & \\
Performance*female & & & & & 0.0261 \\
& & & & & $(0.0173)$ \\
Constant & $0.667^{* * *}$ & 0.0511 & -0.215 & -0.00180 & 0.0636 \\
& $(0.0766)$ & $(0.244)$ & $(0.602)$ & $(1.000)$ & $(0.631)$ \\
Observations & 70 & 70 & 70 & 70 & 70 \\
R-squared & 0.140 & 0.211 & 0.219 & 0.235 & 0.239 \\
\hline
\end{tabular}

Robust standard errors in parentheses

*** $p<0.01, * * p<0.05, * p<0.1$ 
Table 9 Reproductive success and competitiveness in handgrip strength, OLS regression

\begin{tabular}{|c|c|c|c|c|}
\hline & All & All & Males & Females \\
\hline \multirow[t]{2}{*}{ Female } & 0.997 & 0.228 & & \\
\hline & $(0.852)$ & $(0.906)$ & & \\
\hline \multirow[t]{2}{*}{ Age } & $0.317 * * *$ & $0.299 * * *$ & $0.432 * *$ & $0.260 *$ \\
\hline & $(0.114)$ & $(0.110)$ & $(0.203)$ & $(0.144)$ \\
\hline \multirow[t]{2}{*}{$\operatorname{Age}^{\wedge} 2$} & $-0.00319^{* *}$ & $-0.00292 * *$ & -0.00430 & $-0.00281^{*}$ \\
\hline & $(0.00135)$ & $(0.00130)$ & $(0.00264)$ & $(0.00162)$ \\
\hline \multirow[t]{2}{*}{ Competing } & 0.256 & -0.413 & -0.574 & $2.088^{* *}$ \\
\hline & $(0.664)$ & $(0.774)$ & $(0.762)$ & $(0.991)$ \\
\hline \multirow[t]{2}{*}{ Performance } & 0.0244 & 0.0247 & $0.0638^{*}$ & -0.196 \\
\hline & $(0.0405)$ & $(0.0410)$ & $(0.0373)$ & $(0.128)$ \\
\hline \multirow[t]{2}{*}{ Competing*female } & & 1.614 & & \\
\hline & & $(1.359)$ & & \\
\hline \multirow[t]{2}{*}{ Constant } & $-4.931^{*}$ & $-4.227^{*}$ & $-8.409 * *$ & 1.831 \\
\hline & $(2.586)$ & $(2.521)$ & (3.419) & (3.837) \\
\hline Observations & 68 & 68 & 38 & 30 \\
\hline R-squared & 0.140 & 0.165 & 0.264 & 0.218 \\
\hline
\end{tabular}

Robust standard errors in parentheses

$* * * p<0.01, * * p<0.05, * p<0.1$

\section{References}

Ai, C., \& Norton, E. C. (2003). Interaction terms in logit and probit models. Economics Letters, 80(1), 123-129. Alexander, R. D. (1987). The biology of moral systems. London: Aldine.

Almås, I., Cappelen, A.W., Salvanes, K.G., Sørensen, E., \& Tungodden, B. (2012). Willingness to compete: Family matters. Working paper.

Andersen, S., Ertac, S., Gneezy, U., List, J., \& Maximiano, S. (2013). Gender, competitiveness and socialization at a young age: evidence from a matrilineal and a patriarchal society. Review of Economics and Statistics, 95(4), 1438-1443.

Apicella, C.L. (2014). Upper-body strength predicts hunting reputation and reproductive success in Hadza hunter-gatherers. Evolution and Human Behavior, 36(6), 508-518.

Apicella, C. L., \& Cesarini, D. A. (2011). Testosterone and the biology of politics: experimental evidence from the 2008 Presidential Election. In P. K. Hatemi and R. McDermott (Eds.), Man is by nature a political animal: Evolution, biology, and politics (pp. 261-272). Chicago: University of Chicago Press.

Apicella, C. A., \& Crittenden, A. (2015). Hunter-gatherer parenting and families. In D. M. Buss (Ed.), The handbook of evolutionary psychology. Hoboken, NJ: Wiley.

Apicella, C. L., Little, A. C., \& Marlowe, F. W. (2007). Facial averageness and attractiveness in an isolated population of hunter-gatherers. Perception, 36, 1813.

Apicella, C. L., Marlowe, F. W., Fowler, J. H., \& Christakis, N. A. (2012). Social networks and cooperation in hunter-gatherers. Nature, 481(7382), 497-501.

Apicella, C. L., Azevedo, E. A., Fowler, J., \& Christakis, N. C. (2014). Isolated hunter-gatherers do not exhibit the endowment effect bias. American Economic Review, 104, 1793-1805.

Bateman, A. J. (1948). Intra-sexual selection in Drosophila. Heredity, 2(Pt. 3), 349-368.

Bertrand, M., (2010). New Perspectives on Gender. In O. Ashenfelter \& D. Card (Eds.), Handbook of Labor Economics, 4, Part B (pp. 1543-1590). Elsevier. 
Boschini, A., Dreber, A., von Essen, E., Muren, A., \& Ranehill, E. (2014). Gender and economic preferences in a large random sample. Working paper.

Bowles, S. (2009). Did warfare among ancestral hunter-gatherers affect the evolution of human social behaviors? Science, 324(5932), 1293-1298.

Burbank, V. K. (1987). Female aggression in cross-cultural perspective. Cross-Cultural Research, 21(1-4), $70-100$.

Cárdenas, J. C., Dreber, A., von Essen, E., \& Ranehill, E. (2012). Gender differences in competitiveness and risk taking: comparing children in Colombia and Sweden. Journal of Economic Behavior and Organization, 83(1), 11-23.

Clutton-Brock, T. H. (2009). Sexual selection in females. Animal Behaviour, 77(1), 3-11.

Clutton-Brock, T. H., \& Huchard, E. (2013). Social competition and selection in males and females. Philosophical Transactions of the Royal Society, B: Biological Sciences, 368(1631), 20130074.

Clutton-Brock, T. H., \& Parker, G. A. (1992). Potential reproductive rates and the operation of sexual selection. Quarterly Review of Biology, 67(4), 437-456.

Clutton-Brock, T. H., Hodge, S. J., Spong, G., Russell, A. F., Jordan, N. R., Bennett, N. C., et al. (2006). Intrasexual competition and sexual selection in cooperative mammals. Nature, 444(7122), 1065-1068.

Cosmides, L., \& Tooby, J. (1994). Better than rational: evolutionary psychology and the invisible hand. American Economic Review, 84(2), 327-332.

Croson, R., \& Gneezy, U. (2009). Gender differences in preferences. Journal of Economic Literature, 47(2), 1-27.

Darwin, C. (1871). Sexual selection and the descent of man. London: Murray.

Datta Gupta, N., Poulsen, A., \& Villeval, M. C. (2013). Gender matching and competitiveness: experimental evidence. Economic Inquiry, 51(1), 816-835.

Domínguez-Rodrigo, M., Bunn, H. T., Mabulla, A. Z. P., Baquedano, E., Uribelarrea, D., Pérez-González, A., et al. (2013). On meat eating and human evolution: a taphonomic analysis of BK4b (upper Bed II, Olduvai gorge, Tanzania), and its bearing on hominin megafaunal consumption. Quaternary International, 322-323, 1-24.

Dreber, A., von Essen, E., \& Ranehill, E. (2011). Outrunning the gender gap - boys and girls compete equally. Experimental Economics, 14(4), 567-582.

Dreber, A., von Essen, E., \& Ranehill, E. (2014). Gender and competition in adolescence: tasks matter. Experimental Economics, 17(1), 154-172.

Elias, M. (1981). Serum cortisol, testosterone, and testosterone-binding globulin responses to competitive fighting in human males. Aggressive Behavior, 7, 215-224.

Flory, J., Gneezy, U., Leonard, K., \& List, J.A. (2012). Sex, competitiveness, and investment in offspring: On the origin of preferences. Working paper.

Gneezy, U., \& Rustichini, A. (2004). Gender and competition at a young age. American Economic Review, $377-381$.

Gneezy, U., Niederle, M., \& Rustichini, A. (2003). Performance in competitive environments: gender differences. Quarterly Journal of Economics, 118(3), 1049-1074.

Gneezy, U., Leonard, K. L., \& List, J. A. (2009). Gender differences in competition: evidence from a matrilineal and a patriarchal society. Econometrica, 77(5), 1637-1664.

Günther, C., Arslan Ekinici, N., Schwieren, C., \& Strobel, M. (2010). Women can’t jump? - An experiment on competitive attitudes and stereotype threat. Journal of Economic Behavior and Organization, 75(3), 395-401.

Hawkes, K., \& Bliege Bird, R. (2002). Showing off, handicap signaling, and the evolution of men's work. Evolutionary Anthropology, 11, 58-67.

Hawkes, K., O’Connell, J. F., \& Jones, N. G. B. (2014). More lessons from the Hadza about men's work. Human Nature, 1-24.

Henrich, J., Boyd, R., Bowles, S., Camerer, C., Fehr, E., Gintis, H., \& McElreath, R. (2001). In search of homo economicus: behavioral experiments in 15 small-scale societies. American Economic Review, 91(2), 73-78.

Henrich, J., Heine, S. J., \& Norenzayan, A. (2010a). Most people are not WEIRD. Nature, 466(7302), 29-29.

Henrich, J., Ensminger, J., McElreath, R., Barr, A., Barrett, C., Bolyanatz, A., et al. (2010b). Markets, religion, community size, and the evolution of fairness and punishment. Science, 327(5972), 1480-1484.

Henrich, J., Boyd, R., \& Richerson, P. J. (2012). The puzzle of monogamous marriage. Philosophical Transactions of the Royal Society, B: Biological Sciences, 367(1589), 657-669.

Hill, K. R., \& Hurtado, A. M. (1996). Ache life history: the ecology and demography of a foraging people. Hawthorne, New York: Aldine de Gruyter.

Hrdy, S.B. (2005). Comes the child before the man: how cooperative breeding and prolonged postweaning dependence shaped human potentials. Hunter Gatherer Childhoods, 65-91.

Hrdy, S. B. (2009). The woman that never evolved: With a new preface and bibliographical updates. Cambridge, MA: Harvard University Press. 
Ivey, P. K. (2000). Cooperative reproduction in ituri forest hunter-gatherers: who cares for Efe infants? Current Anthropology, 41(5), 856-866.

Kaplan, H. (1994). Evolutionary and wealth flows theories of fertility: Empirical tests and new models. Population and Development Review, 753-791.

Kaplan, H., \& Hill, K. (1985). Hunting ability and reproductive success among male Ache foragers: preliminary results. Current Anthropology, 131-133.

Kaplan, H., Hill, K., Lancaster, J., \& Hurtado, A. M. (2000). A theory of human life history evolution: diet, intelligence, and longevity. Evolutionary Anthropology Issues News and Reviews, 9(4), 156-185.

Keller, L., \& Reeve, H. K. (1994). Partitioning of reproduction in animal societies. Trends in Ecology \& Evolution, 9(3), 98-102.

Khachatryan, K., Dreber, A., von Essen, E., \& Ranehill, E. (2014). Gender and preferences at a young age: Evidence from Armenia. Working paper.

Kramer, K. L. (2005). Children's help and the pace of reproduction: cooperative breeding in humans. Evolutionary Anthropology: Issues, News, and Reviews, 14(6), 224-237.

Kurzban, R., \& Leary, M. R. (2001). Evolutionary origins of stigmatization: the functions of social exclusion. Psychological Bulletin, 127(2), 187.

Lancaster, J. B. (1978). Carrying and sharing in human evolution. Human Nature Magazine, 1, 82-89.

Lancaster, J. B. \& Lancaster, C. S. (1983). Parental investment: the hominid adaptation. In D. J. Ortner (Ed.), How Humans Adapt: A Biocultural Odyssey. (pp. 33-69). Washington, DC: Smithsonian Institution Press.

Lee, R. B., \& Daly, R. H. (Eds.). (1999). The Cambridge encyclopedia of hunters and gatherers. Cambridge: Cambridge University Press.

Lovejoy, C. O. (1981). The origin of man. Science, 211(4480), 341-350.

Marlowe, F. (1999). Showoffs or providers? The parenting effort of Hadza men. Evolution and Human Behavior, 20(6), 391-404.

Marlowe, F. W. (2001). Male contribution to diet and female reproductive success among foragers. Current Anthropology, 42, 755-760.

Marlowe, F. W. (2004). Mate preferences among Hadza hunter-gatherers. Human Nature, 15(4), 365-376.

Marlowe, F. W. (2010). The Hadza: Hunter-gatherers of Tanzania (Vol. 3). Oakland, CA: University of California Press.

Mayr, U., Wozniak, D., Davidson, C., Kuhns, D., \& Harbaugh, B. (2012). Competitiveness across the life span: the feisty fifties. Psychology and Aging, 27(2), 278-285.

Mazur, A., Booth, A., \& Dabbs, J., Jr. (1992). Testosterone and chess competition. Social Psychology Quarterly, 55, 70-77.

McHenry, H. M. (1992). Body size and proportions in early hominids. American Journal of Physical Anthropology, 87, 407-431.

Meehan, C. L. (2005). The effects of residential locality on parental and alloparental investment among the Aka foragers of the Central African Republic. Human Nature, 16(1), 58-80.

Mehta, P.H., Snyder, N. Knight, E.L., Lassetter, B. (2015). Close versus decisive victory moderates the effect of testosterone change on competitive decisions and task enjoyment. Adaptive Human Behavior \& Physiology, Current Issue.

Niederle, M., \& Vesterlund, L. (2007). Do women shy away from competition? Do men compete too much? Quarterly Journal of Economics, 122(3), 1067-1101.

Plavcan, J. M. (2001). Sexual dimorphism in primate evolution. American Journal of Physical Anthropology, $116,25-53$.

Richerson, P. J., \& Boyd, R. (2008). Not by genes alone: How culture transformed human evolution. Chicago, IL: University of Chicago Press.

Rosvall, K. A. (2011). Intrasexual competition in females: evidence for sexual selection? Behavioral Ecology, 22(6), 1131-1140.

Sear, R., \& Mace, R. (2008). Who keeps children alive? A review of the effects of kin on child survival. Evolution and Human Behavior, 29(1), 1-18.

Smith, E. A. (2004). Why do good hunters have higher reproductive success? Human Nature, 15, 343-364.

Snowdon, C. T., \& Pickhard, J. J. (1999). Family feuds: severe aggression among cooperatively breeding cotton-top tamarins. International Journal of Primatology, 20(5), 651-663.

Stanton, S., Beehner, J., Saini, E., Kuhn, C., \& LaBar, K. (2009). Dominance, politics, and physiology: voters' testosterone changes on the night of the 2008 United States presidential election. PLoS ONE, 4, e7543.

Sterck, E. H., Watts, D. P., \& van Schaik, C. P. (1997). The evolution of female social relationships in nonhuman primates. Behavioral Ecology and Sociobiology, 41(5), 291-309.

Stockley, P., \& Bro-Jørgensen, J. (2011). Female competition and its evolutionary consequences in mammals. Biological Reviews, 86(2), 341-366. 
Sutter, M., \& Rützler, D. (2014). Gender differences in competition emerge early in life. Management Science. Tooby, J., \& Cosmides, L. (1988). The evolution of war and its cognitive foundations. Institute for evolutionary studies technical report, $88(1), 1-15$.

Trivers, R. (1972). Parental investment and sexual selection. In B. Campbell (Ed.), Sexual selection and the descent of man, 1871-1971 (pp. 136-179). Chicago, IL: Aldine.

Trumble, B. C., Smith, E. A., O’Connor, K. A., Kaplan, H. S., \& Gurven, M. D. (2014). Successful hunting increases testosterone and cortisol in a subsistence population. Proceedings of the Royal Society B: Biological Sciences, 281(1776), 20132876.

van Vugt, M., De Cremer, D., \& Janssen, D. P. (2007). Gender differences in cooperation and competition the Male-Warrior hypothesis. Psychological Science, 18(1), 19-23.

West-Eberhard, M. J. (1979). Sexual selection, social competition, and evolution. Proceedings of the American Philosophical Society, 222-234.

Wiessner, P. (2002). Hunting, healing, and hxaro exchange: a long-term perspective on! Kung (Ju/'hoansi) large-game hunting. Evolution and Human Behavior, 23(6), 407-436.

Woodburn, J. (1998). Sharing is not a form of exchange: an analysis of property-sharing in immediate-return hunter - gatherer societies. In C. M. Hann (Ed.), Property relations: renewing the anthropological tradition (pp. 48-63). Cambridge: Cambridge Univ. Press.

Wozniak, D., Harbaugh, W., \& Mayr, U. (2014). The menstrual cycle and performance feedback alter gender differences in competitive choices. Journal of Labor Economics, 32(1), 161-198.

Zhang, J. (2013). Culture and the gender gap in competitive inclination: Evidence from the Communist experiment in China. Working paper.

Zilioli, S., Mehta, P. H., \& Watson, N. V. (2014). Losing the battle but winning the war: uncertain outcomes reverse the usual effect of winning on testosterone. Biological Psychology, 103, 54-62. 